\title{
1 Care for the Self - But Not for the Career? Men's Perceptions of Work-related Self-care
}

\begin{abstract}
Research into men's health has found that the potential conflict between health awareness and masculinity centred on paid work has been replaced by men's understanding of health as a competitive edge in working life. In contemporary organisations, being healthy, demonstrating high performance and expressing a willingness to participate in workplace health promotion voluntarily promote one's career. This chapter describes men's agentive encounters with health-related social expectations in Finnish working life. The study focuses on how and why men care for their health in the context of work. The material consists of 18 interviews of men concerning work-related self-care. The study shows that the most prevalent aim of self-care was personal wellbeing, understood as a situation in which most areas of life are enjoyable in a sustained way. To this end, the men coopted disciplined practices that aimed to change or maintain certain qualities of the body and mind. However, this goal of personal wellbeing was supplemented by an aspiration for a balance between work and non-work. The majority of participants felt that self-care was addressed repeatedly in both the workplace and in the media. When participants co-opted recommended practices, this was done critically and for the sake of personal benefit. Thus, the study shows how men practice resistance when they navigate expectations surrounding working life. Concurrently, the participants perceived masculinity as more broadly defined and less binding than before. Besides contributing empirical data to the literature on men's health, this chapter challenges men and masculinity scholars to focus their analytical gaze on men's agency.
\end{abstract}

\section{Introduction}

Industrialisation, the emergence of the wage-labourer class and the entry of women into the labour market took place in Finland late, compared with other Western European countries (Hannikainen and Heikkinen 2006). Until the 1970s, the workforce that consisted mainly of men earned a living largely through the extraction and collection of natural resources as well as manufacturing and construction (Hannikainen and Heikkinen 2006; Turtiainen and Väänänen 2012). At 
the time, Finnish working life constituted a 'field of glory' for men: men's honour was built on visual signs of diligence and success in work that made a visible impact on the external world. In this sociocultural context, externally detectable health issues caused by work were not just understood as a social problem. Instead, indifference towards one's health offered a means for men's positive selfidentification with idealised masculinity (Kortteinen 1992, 47; Pietilä 2008, 149). The careers that were available to most men in agrarian Finland and during industrialisation in the post-World War Two era did not offer extensive opportunities for advancement. However, uninterrupted and prolonged devotion to a single field of work fulfilled the expectations put on men during post-war nationbuilding efforts (Siltala 1994, 153; Turtiainen and Väänänen 2012). Survival despite adversity, rather than personal success or happiness, was respected.

Recent studies on men and masculinities in Western countries indicate a transition towards a wider societal criticism of conventional masculinities and a willingness by men to choose life courses that differ from these conventional models (Bridges and Pascoe 2014). In late modern societies, work is no longer the only or even the most important route to self-esteem-enhancing self-identification for men. Eerola (2015) argues that men in Finland are distancing themselves from the male breadwinner model and moving closer to the intimate and emotional core of the family. Widespread gender equality discourse in the Nordic countries, a geographical and cultural region in Northern Europe which includes Denmark, Finland, Iceland, Norway and Sweden, is destabilising men's faith in traditional ways of being a man and showing them alternatives (Jóhannsdóttir and Gíslason 2018). Thus, abandoning what Biese (2017) terms prevalent masculinist notions about careers, such as linearity and continuous upward progression in organisations, also becomes possible for men.

Concurrently, individual health has turned into an increasingly topical subject in working life. This manifests itself in both informal organisational discourse in which bodies signalling unhealthy lifestyles are increasingly stigmatised (Amsterdam and Eck 2019; Huzell and Larsson 2012), as well as in the rise of formal workplace health promotion that involves physical exercise programmes, nutrition assessments and mental wellbeing screening (Cederström and Spicer 2015; Dailey, Burke and Carberry 2018; James and Zoller 2018). Although the presence of workplace health promotion is apparently justified by its indubitable benefits for both employers and employees in the form of increased stamina, productivity and personal wellbeing (James and Zoller 2018), doing visible work on one's own health is also widely perceived by employers as a way of expressing professionalism, loyalty to the organisation and commitment to the work (Amsterdam and Eck 2019; Cederström and Spicer 2015; Kelly, Allender and Colquhoun 2007; Meriläinen, Tienari and Valtonen 2015). Therefore, this development contributes 
not only to the repertoire of practices that prolong and boost working life but also to the possibilities of climbing up the career ladder. Increased discussion on health in organisations implies a change in the health behaviour of men in their pursuit of career advancement: here self-reliance is replaced by self-management (Connell and Wood 2005, 355; Riach and Cutcher 2014).

However, men's explicit criticism of masculinities centred on paid work may also result in resistance to organisational health discourses. Health discourses in working life, when viewed as a visible form of organisational power distinct from work assignments, can form a site of resistance to the organisation's power over employees (James and Zoller 2018). Concern for one's own wellbeing can also constitute a struggle to survive under conditions of increasing expectations at work or troubling power relations in the workplace (Amsterdam and Eck 2019).

In line with earlier research (Bressi and Vaden 2017; Kelly, Allender and Colquhoun 2007), I define work-related self-care as practices in which an individual scrutinises themselves and decides intentionally to affect his or her mental or physical health and wellbeing in order to resolve current or anticipated problems in working life. Thus, self-care is twofold, including both practices that aim to increase work performance as well as practices that aim to modify the pace and content of work in order to achieve personal wellbeing. In this chapter I draw from evidence of the increased instability of masculinities to rethink men's health and wellbeing in working life. I put forward two research questions: How do men care for themselves in the context of work and careers and with what goals? How do men experience the surrounding norms to limit and enable their self-care and how do they react to such norms? Echoing Taylor (2009), I understand norms as codes of conduct that individuals perceive as conventional or binding and as subject to either conformity or resistance. In this chapter I focus on norms relating to masculinity as well as norms related to success in the labour market and in a particular workplace. A qualitative design is pursued using empirical data gathered from 18 semi-structured one-to-one interviews. The data was collected with the aim of including men from different socioeconomic backgrounds based in Greater Helsinki, Finland.

I argue that participants aimed for both sufficient performance at work and a meaningful personal life by taking care of their health through exercise, diet modification and rest, as well as restricting the time and personal resources allocated to work. In order to achieve personal wellbeing, participants sometimes resisted external models of self-care that they felt conflicted with their personal life goals unrelated to work. However, participants felt that the surrounding norms of masculinity did not prevent them from pursuing such a balance. Previous research has focused on how complying with the ideal of health has become part of dominant masculinity in working life. These studies have somewhat 
ignored socioeconomic differences between men, as they have focused on men who pursue an ascending career path in knowledge-intensive work. The present study contributes to this discussion by showing that there are working life contexts and localities in which dominant masculinities centred on competition are perceived by men but do not constitute a meaningful goal for them. Men in Finnish working life expressed attitudes that do not connect self-care to organisational discourses or hierarchies between men but on personal wellbeing instead.

The remainder of this chapter is structured as follows. I begin with a brief discussion of men's agency against the background of Finnish society. Thereafter, I discuss the study's data and methods. There are four subsections illustrating the findings. I end with a summarising discussion and conclusions.

\section{Co-optation and Resistance: Towards Agency in Critical Studies on Men and Masculinities}

Recent discussions in critical studies on men and masculinities have focused on the rapid change in expectations concerning men and the consequences of these changes on the behaviour and gender performances of men in, for example, workplaces. In these discussions, the concept of hegemonic masculinity, defined as a way of being a man that is both culturally exalted and complied with by the majority of men (Connell and Messerschmidt 2005), has been found to be insufficient. As an outcome, new masculinities, such as "hybrid masculinity", defined as "men's selective incorporation of performances and identity elements associated with marginalised and subordinated masculinities and femininities" (Bridges and Pascoe 2014, 246) that is performed due to the devaluation of "hegemonic capital" (253) have been constituted to explain men's behaviour. In the context of men's health, Pietilä (2008) outlines "today's hegemonic masculinity" (9) to describe men's increasing interest in health issues and their willingness to renegotiate gendered meanings related to health in Finnish society.

Previously, the unity, stasis and influence of hegemonic masculinities have often been exaggerated in order to understand men's health behaviour (Matthews 2016; Robertson, Williams and Oliffe 2016). Waling (2019) argues that although hegemonic masculinity and its derivatives successfully describe societal power relations between different groups of men and women, this theoretical tradition does not illuminate men's agentive and affective encounters with gendered expectations. Categorical analyses have shortcomings as regards both men's lived experiences (Berggren 2014; Hearn 2012, 311) and men's agency and emotional reflexivity, understood as the capacity for one to act in a particular environment 
that consists of a variety of constraints and relations of power without reproducing pre-existing models of masculinity (Petersen 1998, 117; Waling 2019). Rather than abandoning masculinity as an explanatory framework, its critics aim to moderate its explanatory power. For example, in some social contexts, health may arise as a more valuable social achievement than being recognised as a 'real' man (Farrimond 2012).

Heyes argues that an analysis of self-care should always presume the agency of individuals. In my analysis I draw from her conception of self-care as “co-optation and resistance" (Heyes 2007, 85). This notion refers to a wide range of mutually conflicting self-care practices based on diverse conceptions of healthiness available in Western societies, from which individuals choose their modes of operation. This choice happens in a particular environment, where subordination to norms set by other people can also lead to pleasures and benefits despite the potentially painful nature of the process. Crocket (2017) fortifies this argument by pointing out that separating self-care as "critical self-awareness" (35-36) from docility to external ideals questions the value of the lived experience of research subjects on arbitrary grounds.

I claim that men evaluate their possibilities for action from the viewpoint of their personal lived experiences and orient themselves to a range of threats, sanctions and possibilities around them (Berggren 2014). However, I suggest that the wider local sociocultural context, such as the emerging gender equality discourse changing the content of idealised masculinities in Nordic countries, should also be taken into account. Thus, diverging from the Connelian tradition does not mean that social hierarchies between masculinities should be abandoned as a target of analysis. Instead, subordination and exaltation of certain masculinities should be understood as relatively incohesive systems of thought and thus unstable and subject to change by locality and time (Petersen 1998, 116-117), although these discourses also affect material and social practices (Hearn 2012, 315).

In addition to emerging gender equality discourse, two distinct circumstances in the Finnish sociocultural context shape masculinities. Jukarainen (2014) argues that compulsory military service that affects only men, and Finland's belligerent past in comparison to other Nordic countries have turned military virtues into general men's virtues: historically, this model has compromised men's expressions of personal needs. Secondly, late industrialisation in comparison to other Nordic countries, strong occupational segregation of work as well as entrepreneurial attitudes dominant in small-scale independent farming have historically accustomed men to see work as the primary basic principle guiding their lives (Turtiainen and Väänänen 2012).

In the following I will show how these ideals were recognised and their values renegotiated by participants who acknowledged that some traditional ways of 
being a man conflicted with their wellbeing. Moreover, participants experienced themselves as subjects of workplace health promotion during work hours. Although participants found these interventions potentially helpful, the criticism of lifestyles centred on work provided them with the ability to consider the meanings of this phenomenon and partly resist it (see Dailey, Burke and Carberry 2018; James and Zoller 2018). Thus, men's awareness of traditions and expectations surrounding them as men and workers did not determine their actions but gave them the opportunity to question and resist these modes of being.

\section{Method}

This chapter draws from 18 semi-structured interviews conducted in 2017 and 2018 in different work sectors: media $(\mathrm{N}=7)$, social services and healthcare $(\mathrm{N}=7)$, and logistics (N=4). Participants identified as men and lived in the Greater Helsinki area. Participants were contacted by approaching trade unions in Greater Helsinki, and also through both snowballing via existing study subjects and the author's personal contacts. Because work-related self-care among men has previously been connected to highly educated workers in knowledge-intensive work, I aimed at wider socioeconomic coverage and representativeness in the data collection process: I focused on three fields with different education requirements, different factors producing work-related stress and differences in gender segregation. All men worked in fixed-term or permanent employment relationships. Two participants had more than one job, one as an employee in two organisations, and one as both an employee and a self-employed person. Four participants worked in managerial positions. Although the focus on employed men was unintended, it helped me focus my analysis on the social and normative aspects of working life.

Greater Helsinki includes the smaller Capital Region and commuter towns surrounding Helsinki, the capital city of Finland. As the largest urbanised area in Finland with large inwards migration from other parts of the country, Greater Helsinki represents great variance in working conditions and Finnish local cultures. Helsinki is an example of a post-industrial Nordic region in which industry jobs have been replaced by service sector jobs. Greater Helsinki belongs to the region of Uusimaa where the population is more highly educated on average than in other parts of Finland.

Six out of seven participants in both the media and healthcare sectors held bachelor's degrees or higher. I supplemented the data by interviewing men who work in logistics, which differs from the two previously mentioned fields 
in being both male-dominated and, in many instances, requiring no formal education. All of the participants working in logistics had only secondary education, and only one had an education corresponding to his field of work.

As the sampling proceeded, I focused the recruitment of participants on men who were not between 35 to 45 years old, heterosexual, highly educated, and white ethnic Finns, as interviews of these men constituted the majority of the data. The average participant age was 39 years, with participant ages ranging from the early 20 s to the late 50s. Although themes raised by the interviewer did not include sexuality, three men stated that they lived in non-heterosexual intimate relationships. Most of the participants made references to heterosexuality. All participants were able-bodied. Two participants stated that they had an illness that demanded regular treatment. My original aim to include in the sample interviews a variety of men from different socioeconomic groups, age groups, sexualities and ethnicities only partially succeeded. Despite the presence of men of different fields, ages and sexualities, the overwhelming majority of interviewees, with one exception, were white, ethnic Finns. In addition, the generalisability of the findings drawn from the data is also limited by the relatively small geographical context and spontaneous participation of interviewees. Participation was voluntary. Therefore, it is worth noting that men who did not find self-care to be a relevant matter in their lives were unlikely to participate and men who participated often had a thoughtout opinion on the topic that they wanted to share. For example, several participants reported that they had found the expectations put on them as men to be problematic and they wanted to instigate resistance to these expectations by participating in the study.

The themes covered in the interviews were matters affecting wellbeing in the workplace, the meanings and contents of work-related self-care, respondents' own practices of work-related self-care, and how gender identity influenced work-related self-care in both the participants' lives and in Finnish society. Besides these themes, other topics, such as the impact of workplace health promotion on self-care, were introduced by the participants themselves.

I looked for a balance between an endeavour towards gender equality and an interest in learning more about what men think and feel about self-care as follows. Flood (2013) points out that when a man interviews a man, the homosociality between men is a double-edged sword. It is desirable that the interview is perceived as a shared project between two men in which the participant's experiences as a man are valued. However, homosociality may also be perceived as a natural context for practices in which masculine identity is performed in front of other men through, for example, sexually objectifying behaviours. In line with Flood, I avoided participating in masculinity performances that included sexism, racism or homophobia, and I was willing to refuse to give room to these ideas in 
the interview situation. However, I experienced no need for such an intervention during the interviews. Studies addressing self-care as an empowering practice may focus too keenly on what the analyst sees as structurally significant agency (Crocket 2017, 35-36). Thus, I was determined not to challenge participants' conceptions of what they understood as favourable or functional self-care.

Thematic analysis was used to analyse the data (Braun and Clarke 2006). While employing this methodology, researchers should make an intentional choice between 'semantic' and 'latent' themes, that is to say, analysis of semantic patterns and analysis of ideas, assumptions, and conceptualisations that may be expressed differently in different contexts (84). My analysis follows the strategy focusing on latent themes: I assume that speech expresses attitudes that have material consequences in the lives of the participants. It indicates both conceptual schemas that delimit understandings and deployment of concepts and categories in order to achieve specific political goals (Bacchi 2005).

The data were read and coded for themes related to my research questions. The analysis began with coding the data manually using descriptive content analysis, which meant dividing the data into meaning units. One meaning unit consisted of an utterance, which held a single thought, opinion or idea. Second, similar codes were divided under thematic categories. In the final analysis all categories produced were reviewed and named. Only themes that I considered strong enough are presented in the following section. These themes were constructed around at least one code that was present at least once in more than half of the 18 interviews. Also, less commonly occurring codes were included under these themes as long as they supported and deepened the ideas of more prevalent codes.

\section{Findings: Men Renegotiating their Positions on Careers and Health at Work}

I identified two repeating themes related to both research questions I put forward in the beginning of this chapter. First, I analysed how men cared for themselves and what goals they set for their self-care. Participants reported that their workrelated self-care mostly included practices affecting bodily and mental health with the aim of achieving long-term personal wellbeing. Moreover, this theme of personal wellbeing was supplemented by an aspiration to balance work and nonwork. Men expressed concern for themselves in light of both understanding paid work as a personal duty and the experience of pressure to spend more of their limited personal resources on work than they found reasonable. Here the personal 
significance of advancing and/or prolonging a career in a single field or workplace was downplayed.

Second, I analysed how men experienced surrounding norms as limiting and/or enabling their self-care and how they reacted to these norms. Participants felt that their employer directed them towards certain forms of self-care that increase work performance. This was understood as a potentially ominous state of affairs: external tips concerning self-care were understood as useful, but they also included a risk of exploitation. Concurrently, participants experienced that their engagement with practices previously associated with subordinated masculinities and femininities was less regulated than among previous generations of men. Under changing social pressures, the majority of the respondents felt that certain employer-driven forms of self-care that signal loyalty to the employer were more binding than being a certain kind of man. The following four empirical sections address the four themes interpreted in greater detail. All names are pseudonyms.

\section{Personal Wellbeing}

During the interviews, participants produced numerous different understandings of practices to be counted as self-care. In speech, the most prevalent aim attributed to self-care was wellbeing, understood as a situation in which most areas of life are enjoyable in the long run. To illustrate this point, Pasi separated the activities that promote long-lasting wellbeing from the activities that produce mere pleasure. He saw the use of intoxicants to deal with stress as counterproductive:

Pasi: There is true self-care, and then there is specious self-care, in which you just escape your problems. For example, drinking liquor: that is not self-care, in a way you just postpone your problems until the next day. If a guy cares for himself, it includes going to the movies, seeing friends, eating out, having pleasurable free time, walking outside, travelling. (Media, 35-39 y.)

In addition to choosing free time activities that were both pleasant and not unhealthy, respondents also practiced discipline that aimed to change or maintain certain qualities of the body and mind, including rest, exercise, and restrictions on the consumption of intoxicants and food. "Treating one's body as a thing to be managed" (Connell and Wood 2005, 355), which has not been perceived as socially acceptable for men by men in all sociocultural contexts, was clearly understood as necessary in working life: 
Interviewer: If you think about your current job and your ability to stay in it, what do you understand as the most important forms of self-care you should practise?

Sami: [ . . . ] Well, if you think about concrete ones. You must sleep enough, and go to bed early. It is very important, although I'm quite bad at it. (laughter) I often stay up a little bit longer than I should. And a healthy diet, exercise. I try to exercise a little bit so I can keep going. (Social services and healthcare, 40-44 y.)

Sami's self-care aimed at an appropriate use of self in a professional role by pursuing high performance and an absence of fatigue. However, participants perceived their work on their own health as separate from the informal organisational discourses that create competition and hierarchies between individuals. These discourses include recognising colleagues as competitors (Connell and Wood 2005), comparison between individuals (Amsterdam and Eck 2019; Huzell and Larsson 2012; Meriläinen, Tienari and Valtonen 2015), expressing professional value (Kelly, Allender and Colquohon 2007; Riach and Cutcher 2014), or expressing loyalty to an employer (Cederström and Spicer 2015, 32). Instead, participants aimed at coping with work, also by restricting the resources spent on it:

Kimmo: I think I have gone through a change in the last two years. I have learned all sorts of survival mechanisms for [work]. I have also realised that as a superior I cannot intervene in everything. I call it the 'Oh dear!' technique: sometimes you just have to raise your hands and say: 'oh dear, there's nothing I can do, just try to manage your job'. (laughter) In a way, I have arrived at a situation in which I must protect my own stuff, my own mental health. (Social services and healthcare, 50-54 y.)

Kimmo felt that the interests of the organisation he works for may conflict with his own interests. He had to restrict the time and effort he put into his professional role as a head nurse in order to promote personal wellbeing and to use himself in other contexts too, apart from work. Kimmo's narrative demonstrates how respondents were ready to compromise their loyalty to organisations. Men did not want to boost their wellbeing in order to become a more productive and reliable worker. Instead, most respondents understood wellbeing as a resource that should be protected from the organisation.

\section{Aspiration to Balance}

Men understood work as their duty, and stressed that their self-care was not about prioritising self over work in every situation. What Bacchi (2005) terms schemas that delimit understandings appeared here: respondents constructed material preconditions that delimited possibilities to protect the self against the work. Sami, a nurse in his early 40s, reasoned that: "It isn't possible that everyone would just 
indulge in unemployment in a way that 'I'm not interested in working, and I'm just not going to work"'. The majority of participants understood self-care as a conscious aspiration for a balance between work and non-work. John, who had immigrated to Finland in his late 20s, appreciated his upbringing for teaching him an attitude to work that he found relatively rare in Finland:

John: I was raised well in a way that work is work and not your whole life. It is important that, if you were like me as a student, you could be as drunk as ever, but you worked, period. My parents said that you can party, but you will still go to the lecture the next day. [ . . . ] I talked with my wife about how Finnish people are very committed to work. Sometimes you must protect yourself from it and keep a distance. One shouldn't always be a kind person. [ . . . ] I sometimes joke about it at home. 'Is this the Winter War?' You see, in the Winter War too you had to be alone and survive. (Social services and healthcare, 40-44 y.)

John, and the majority of the respondents, wanted to make sure that while a share of their personal time and resources were allocated to work, they could still regulate the size of that share. Ari, a journalist in his early 40s, felt he wanted to intentionally and vigorously protect his free time against pressure to work more: "The salary defines the product I'm selling to an employer. Now it's seven and a half work hours per day, and that's it". Thus, men did not attach their self-care to work as a central source of positive self-identification, but to the possibility of using the self in non-work activities instead. Furthermore, they did not strive for increased performance in work or being identified by other people, especially superiors, as "professional, entrepreneurial, resilient" (Kelly, Allender and Colquohon 2007, 267). Instead, participants described their self-care in terms that included the possibility that other people might be visibly more willing to devote more of their personal resources to work.

Furthermore, participants linked the ideal of balancing work and non-work to the responsibility of the employer. After demonstrating a certain amount of reliable work performance, men felt that it was their employer's duty to help them rather than their duty to suit their employer. John stated that he was willing to urge the employer to take responsibility. He compared this to behaviour by his co-workers which he found unhealthy: "Some men in work try to be cavemen. [ . . . ] If we're having a party, they drink a whole bottle of gin in order to relieve stress. I try to take care of [stress] beforehand. I don't find it problematic to talk to my superior if I am scared at work". John drew from the interpretative repertoires that view men's reluctance to help seeking in derisively (Farrimond 2012), when he refused to be a 'caveman': someone who is emotionally reticent with his superiors to achieve honour through selfreliance and exaggerated shows of productivity. 
As part of regulating the use of personal resources, men also questioned career models attached to traditionally idealised masculinities (see Biese 2017): when respondents felt an incompatibility between themselves and their work, they were willing to change their work instead of reshaping themselves. John, who found his shift work wearing, was actively preparing the way for a change in his career: “After doing this for eight years, I don't want to see myself in this job in another five years. I'll start doing something completely different”. John did not find a focus on a single organisation or work field and career progression within it to be a potential source of experiencing success. Instead, he saw work as an obligatory task to be managed in a way that supported his personal wellbeing and other life goals.

\section{External Power: Critical Co-optation and Intentional Resistance}

The majority of participants felt that their employer offered them help on self-care and that self-care was addressed repeatedly in both the workplace and in the media. Men perceived these messages as a use of power to which they were subjects:

Esko: It is parroted on the intranet. There are schedules for group exercises in most elevators. I understand it as a message from our employer: 'remember to take care of yourself!' However, it's more like a supply from which to choose and not an accusation. [ . . . ] Ordinary people go [to social media] to say how much they exercise and how pleasurable it is. [ . . . ] We talk about it at home: Should we eat salad or steak, and should we watch TV or go for a walk? It’s everywhere! (laughter) (Media, 35-39 y.)

Although Esko perceived himself as subjected to various suggestions, he also perceived himself as free of compulsion and able to choose the self-care practices that suit him. Co-optation was critical: although the presence of certain discourses may be motivated by their benefit to the employer or commercial interest, intervention in personal health behaviour may also be beneficial for the individual (see Dailey, Burke and Carberry 2018). Thus, respondents did not experience principled reasons to cease self-care activities inspired by, for example, the superior:

Sami: Our former head nurse told me once that people who work in mental health are always open. Every patient opens something in yourself, maybe your own traumatic memories or something like that. No-one has a completely trauma-free life history, and it makes us vulnerable. The work may turn out to be dangerous. This is a question that I 
have been working on lately. [ . . . ] How to prevent the patients from triggering my traumatic memories? (Social services and healthcare, 40-44 y.)

In line with Pietilä (2008) on the development of men's health behaviour in Finland, Sami stressed the rationality of his stance.

However, usefulness and rationality from the individual viewpoint also marked the boundary of acceptable organisational power on the self-care practised by employees and constituted resistance (see James and Zoller 2018). For example, Miska interpreted workplace health promotion as an attempt to use power over employees in order to fulfil the needs of employers, and against this particular background he expressed concern for his own wellbeing:

Miska: The models of self-care are pretty much learned. They are offered to us, and they come to us from outside. [ . . . ] I recognise it in myself that I've learned, listened and read about those models that may be beneficial for me, and then I've tried them in order to find out if they work for me. [ . . . ] There are many aspects of occupational wellbeing in which it is important to intervene in the work itself and the ways it's done. [ . . ] My employer offered us mindfulness services, and the question crossed my mind: Is this about patching up problems that are caused by something else? (Media, 25-29 y.)

Miska acknowledged that in order to practise self-care one must take in some external guidelines. However, Miska wanted to choose these guidelines himself. He felt that neither loyalty to the employer nor the employer's willingness to increase his work performance from its current state were valid reasons to practise self-care. Therefore, the workplace health initiative provoked resistance in him.

Moreover, the majority of the respondents argued that self-care should be understood as a private matter. They felt that their colleagues were both conscientious and rational enough to have authority over their own self-care practices. Men also explicitly resisted the use of self-care as a form of horizontal power in an organisation. Health was not to be understood as a site of comparison and stigmatisation between individuals (cf. Amsterdam and Eck 2019):

Mauri: I've seen that some people come to work although they need to vomit during breaks. For other people, it's just a little flu or backache, and they go on sick leave for two weeks. It is a personal thing how you perceive yourself. Everybody knows their own body and has experience of how much it can take. I know it for myself and know when I have to admit that I cannot work anymore. (Logistics, 20-24 y.)

Osmo: I'm not going to force my own ideas on my colleagues. I can give tips and share my own experiences, but I'm not assuming that my colleagues should adopt them and do things my way. However, it may be very interesting to listen to, for example, a colleague of mine who has tried a vegetarian diet. [ . . . ] 
Interviewer: What would be the negative consequences of pushing ideas?

Osmo: Other people might find it unpleasant or irritating. (Social services and healthcare, 30-34 y.)

In contrast to previous takes on masculinities (see Riach and Cutcher 2014) and health (Amsterdam and Eck 2019; Huzell and Larsson 2012) in organisational contexts, men did not perceive their workplace as a site of competition and they also refused to understand talking about self-care as way of expressing a higher work ethic in comparison to their colleagues. However, men understood workplace health promotion and collegial tips as potentially beneficial and useful if their contents were critically examined first.

\section{Plural Masculinities and Decreasing Social Pressure}

Participants perceived masculinities as plural external models of being a man that can be either co-opted or resisted:

Interviewer: Is it appropriate for a man to be concerned for himself or care for himself?

Kimmo: I think it should be. It's not only appropriate but necessary. In these things you must be selfish, to a certain extent. You must be selfish because the truth is that we, as men, sacrifice ourselves. I'm not sure if it's like that anymore, but at least that's the traditional picture of men. A bloke goes and does everything. (Social services and healthcare, $50-54$ y.)

Kimmo argued that for men it is conventional to refuse self-care. This "traditional picture of men" resembles the understanding of hegemonic masculinity by Robertson, Williams and Oliffe (2016, 59-60), which includes self-reliance and neglecting personal wellbeing in order to work, as well as understanding work as a source of respect and positive self-identification. However, Kimmo also perceived a better alternative for it: "Sometimes I've been forced to admit that 'heck, I'm tired', and I've actually experienced it as a good thing”. Here, his disidentification from the "traditional picture of men" was not only due to rational reflection, but also to the good feeling it gave him. Here it is evident that Kimmo had found his affective relationship to self-care and men's social role restricting in his own life and had motivated him to participate in the study.

Men perceived pressures to comply with a certain masculinity as real for people who live within a particularly strict code of masculinity. However, participants felt they were free to choose their mode of being from among more than one option. An awareness of masculinity as something men do and 
perform (see Waling 2019), as well as the plural masculinities available (see Jóhannsdóttir and Gíslason 2018), enabled men to modify these gender scripts and react to them affectively. This appeared to be increasingly possible due to the perceived structural changes in the sociocultural context of the men interviewed. For Riku, self-care through scrutinising personal experiences of tiredness did not conflict with the surrounding norms:

Riku: No-one asked [my grandfathers] anything when they came back from the war. They both made their living from agriculture. Army uniforms were thrown away and they went to work in a field. You were allowed to keep your own traumas inside your head and pass them on to the next generation. [ . . . ] It has been a quite big taboo in Finnish society, and all around the world. Nowadays it's not such a stigma anymore to talk about it if you feel tired at work. (Social services and healthcare, 40-44 y.)

Riku interpreted emotional reticence as socially beneficial in the sociocultural setting of the past. In that sociocultural setting, "soldiering-citizenship" (Jukarainen 2014, 92) was admired. However, respondents did not find this to be just a mutual code of conduct shared by men who actually fought in the war. For example, Ari argued that it was also further enhanced through explicit messages to, and expectations put on, men and boys of the next generation:

Interviewer: Is it appropriate for a man to care for himself?

Ari: It is for men of my age. I'm in quite a privileged position in comparison to men who are older than me. I have grown in a community in which there are very strong expectations of being a man, men's work, and men's behaviour. [ . . . ] Our parents made it clear to my generation that men are obliged to do military service. Due to the heritage of wartime, men are men and they do men's work. (Media, 40-44 y.)

The majority of the participants felt that their surroundings enabled "selective incorporation of performances and identity elements associated with [ . . . ] femininities” (Bridges and Pascoe 2014, 246). Participants also understood themselves as more rational and health-aware than men of earlier generations (see Pietilä 2008), and for them, this selective incorporation was part of that line of development:

Mikko: I sometimes laugh when I tell someone I'm the only man [in a group exercise class]. [ . . . ] But that is what makes me laugh. Body maintenance is the same for men and for women. Our bodies do not differ that much from each other. We should all bow and stretch, turn our bodies to the left and right and check that everything is moving. (Media, 40-44 y.)

Mikko experienced indifference towards certain masculinities: although they are present, they can also be ignored. For the participants, effectiveness was a more important factor in self-care than its potential conflict with their identification as men. 
Although the conflict between masculinity and self-care was understood as artificial, there were differences between respondents in how they perceived their possibilities to act freely. This freedom was available mostly to men who occupy knowledge-intensive work (see Bridges and Pascoe 2014; Farrimond 2012). Echoing earlier analysis of men's lived experiences (Berggren 2014; Hearn 2012), some respondents perceived the norms of masculinity as obligatory under threat of sanctions:

Elmeri: A Finnish man does not complain. He just does his work.

Interviewer: Is this still a valid model today?

Elmeri: In my lovely workplace, attitudes change slowly. There you can find these relics from the distant past. Come on! They are uneducated people.

$[\ldots]$

Interviewer: How does it affect your actions?

Elmeri: There are things I would never talk about in my workplace. (Logistics, 30-34 y.)

Elmeri experienced that his social surroundings did not enable him to engage in certain visible self-care practices. However, his personal understanding of change, despite being slow, constructed a plurality of masculinities available for men in Finnish society. Elmeri also understood the slowness of this change as part of his workplace and the socioeconomic characteristics of his colleagues, suggesting that, generally, change which allows men's work-related self-care was a positive thing and actually happening. However, Elmeri felt that this change was more rapid in other contexts of Finnish society and in other fields of work.

\section{Discussion and Conclusions}

Through interviews with 18 men living and working in Greater Helsinki, Finland, this study uncovered the hows and the whys of men's work-related self-care. Following recent discussions on men and masculinity studies, I focused on men's agency and applied the concepts of co-optation and resistance in my analysis. The analysis showed that men considered personal wellbeing as well as the balance between work and non-work as the primary goals of their self-care. Although participants did not resist workplace health promotion for principled reasons, it was repeatedly perceived as a use of power that potentially conflicted with their efforts toward personal wellbeing. Men perceived that there was more 
than one model of masculinity available to them in the surrounding society, from which they chose to practise the one that was compatible with their personal needs. For the majority of participants, this included co-optation of performances associated with what have been previously understood as femininities and subordinated masculinities. However, due the socioeconomic coverage of the data, the social surroundings of the participants, including the masculinities accepted in their workplaces, varied. Therefore, this free borrowing was not always possible, but instead affected by socioeconomic contexts (see Bridges and Pascoe 2014; Farrimond 2012).

Differing from earlier research on the intersections of men, masculinities and health in work, the findings of this study suggest that men practise self-care for other reasons than to build their professional identity and to promote their career. The majority of the participants described their self-care as practices that aim towards personal wellbeing and a balance between work and non-work. Non-work was constituted as being as valuable as work. On the other hand, participation in working life was justified through the material necessity of supporting oneself as well as society and its public infrastructure. Here the majority of the participants did not describe positive self-identification as a core meaning of their work. Thus, the conception of men as evaluating themselves through achievements in paid work, a claim also questioned by earlier research on men and masculinities in Nordic countries (Eerola 2015; Jóhannsdóttir and Gíslason 2018), was further disputed. This way of being a man produced a strong affective reaction from the respondents, manifested in speech that expressed fear, frustration and mockery. Men found the interview situation to be a relaxed and natural situation in which to express such feelings and make them public.

However, the participants felt that the normative aspects of their surroundings were not always compatible with their endeavours. They reported that workplace health promotion encouraged the management of the self towards higher performance and resistance to stress in a way that was contrary to their personal ambitions. Participants stated that they perceived themselves as distancing themselves from this model. This rejection was not complete, as participants also felt that they were able to co-opt certain useful practices from wellness discussions in the media and the workplace. Although, in the words of Miska, "the models of self-care are pretty much learned", this learning was selectively taken up in accordance with the respondents' other lived experiences and beliefs. Thus, having agency in deciding on the forms and aims of self-care was crucial to being a subject who wanted to care for himself. The need for self-care was often articulated alongside an explicit critical attitude toward workplace health promotion, the gendered expectations on men's behaviour in Finnish society and one's own earlier behaviour. Using Waling's (2019) poststructural understanding 
of men's agency as a springboard, I argue that self-care or hybrid masculinity were not worldviews with designated behaviours, practices, morals and goals. Instead, they were something that men chose to do as a reaction to the intersecting relations of power affecting them. Here, theorisations based on men's participation in masculinities that regulate their behaviours lack explanatory power.

The findings of this study have two practical implications for men's health in working life. First, this study helps to rethink men's health in working life without reference to competition and hierarchies among men. This was achieved by a wider socioeconomic coverage compared to previous research. In addition, the research design in which respondents were asked to define self-care and describe their methods of self-care in relation to working life contributed to this result, as the organisational viewpoint on health promotion was not emphasised by the interviewer. Through this remark, health services, including workplace health promotion, targeted at men can also be rethought from a viewpoint that gives more consideration to men's increased willingness to act non-competitively, care for their health and use their time and personal resources for something other than work. Second, Eerola's (2015) claim that Finnish men are defying work-oriented masculinity received new support. The participants of this study understood this defiance as a form of caring for one's own health and wellbeing. Thus, my research helps organisations to prepare for societal change in which society and employers can no longer count on men's continual willingness to prioritise work over other aspects of their lives. In particular, men's increased criticism of masculinities centred on work foreshadows men's transverse movement in between organisations, fragmentary careers and their interest in more personally meaningful careers. Men's increased interest in work-related self-care does not automatically imply docility to any other principle guiding them in working life.

Acknowledgements: I thank Marjut Jyrkinen, Jukka Lehtonen, and Linda McKie, as well as Kadri Aavik and Josephine Hoegaerts, for their insightful and helpful feedback on earlier drafts of this chapter. This work was funded by Academy of Finland (Strategic Research Council) [Grant number: 292883] and the doctoral programme Gender, Culture and Society at the University of Helsinki. 


\section{References}

Amsterdam, Noortje van, and Dide van Eck. 2019. “'I have to go the extra mile.' How fat female employees manage their stigmatized identity at work." Scandinavian Journal of Management 35(1): 46-55.

Bacchi, Carol. 2005. "Discourse, Discourse Everywhere: Subject 'Agency' in Feminist Discourse Methodology.” NORA - Nordic Journal of Women's Studies 13(3): 198-209.

Berggren, Kalle. 2014. "Sticky Masculinity: Post-structuralism, Phenomenology and Subjectivity in Critical Studies on Men." Men and Masculinities 17(3): 231-252.

Biese, Ingrid. 2017. Opting Out and In. On Women's Careers and New Lifestyles. London: Routledge.

Braun, Virginia, and Victoria Clarke. 2006. "Using thematic analysis in psychology." Qualitative Research in Psychology 3(2): 77-101.

Bressi, Sara, and Elizabeth Vaden. 2017. "Reconsidering Self Care.” Clinical Social Work Journal 45(1): 33-38.

Bridges, Tristan, and C. J. Pascoe. 2014. "Hybrid Masculinities: New Directions in the Sociology of Men and Masculinities." Sociology Compass 8(3): 246-258.

Cederström, Carl, and André Spicer. 2015. The Wellness Syndrome. Cambridge: Polity Press.

Connell, Raewyn, and James Messerschmidt. 2005. "Hegemonic masculinity: Rethinking the concept." Gender and Society 19(6): 829-859.

Connell, Raewyn, and Julian Wood. 2005. "Globalization and Business Masculinities." Men and Masculinities 7(4): 347-364.

Crocket, Hamish. 2017. "Problematizing Foucauldian Ethics: A Review of Technologies of the Self in Sociology of Sport Since 2003." Journal of Sport and Social Issues 41(1): 21-41.

Dailey, Stephanie, Tricia Burke, and Emmalene Carberry. 2018. "For Better or For Work: Dual Discourses in a Workplace Wellness Program." Management Communication Quarterly 32 (4): 612-626.

Eerola, Petteri. 2015. Responsible Fatherhood. A Narrative Approach. Jyväskylä: University of Jyväskylä.

Farrimond, Hannah. 2012. "Beyond the caveman: rethinking masculinity in relation to men's help-seeking." Health 16(2): 208-225.

Flood, Michael. 2013. "Negotiating Gender in Men's Research among Men." In Men, Masculinities and Methodologies, edited by Barbara Pini and Bob Pease, 64-76. Basingstoke: Palgrave Macmillan.

Hannikainen, Matti, and Sakari Heikkinen. 2006. "The Labour Market, 1850-2000.” In The Road to Prosperity. An Economic History of Finland, edited by Jari Ojala, Jari Eloranta and Jukka Jalava, 165-186. Helsinki: Suomalaisen Kirjallisuuden Seura.

Hearn, Jeff. 2012. "Male Bodies, Masculine Bodies, Men's Bodies: The Need for a Concept of Gex." In Routledge Handbook of Body Studies, edited by Brian Turner, 307-320. London: Routledge.

Heyes, Cressida. 2007. Self-transformations: Foucault, Ethics, and Normalized Bodies. New York: Oxford University Press.

Huzell, Henrietta, and Patrik Larsson. 2012. "Aesthetic and Athletic Employees: The Negative Outcome of Employers Assuming Responsibility for Sickness Benefits." Economic and Industrial Democracy 33(11): 103-123. 
James, Eric, and Heather Zoller. 2018. "Resistance Training: (Re)shaping Extreme Forms of Workplace Health Promotion.” Management Communication Quarterly 32(1): 60-89. Jóhannsdóttir, Ásta, and Ingólfur Gíslason. 2018. "Young Icelandic Men’s Perception of Masculinities." Journal of Men's Studies 26(1): 3-19.

Jukarainen, Pirjo. 2014. "Men Making Peace in the Name of Just War. The Case of Finland." In Making Gender, Making War: Violence, Military and Peacekeeping Practices, edited by Annica Kronsell and Erika Svedberg, 90-103. New York and London: Routledge.

Kelly, Peter, Steven Allender, and Derek Colquhoun. 2007. “New Work Ethics?: The Corporate Athlete's Back End Index and Organizational Performance." Organization 14(2): 267-285.

Kortteinen, Matti. 1992. Kunnian kenttä: Suomalainen palkkatyö kulttuurisena muotona [Field of Glory: Finnish Paid Work as a Cultural Form]. Helsinki: Hanki ja jää.

Matthews, Christopher. 2016. "The appropriation of hegemonic masculinity within selected research on men's health.” NORMA: International Journal for Masculinity Studies 11(1): 3-18.

Meriläinen, Susan, Janne Tienari, and Anu Valtonen. 2015. "Headhunters and the 'ideal' executive body." Organization 22(1): 3-22.

Petersen, Alan. 1998. Unmasking the Masculine: "Men" and "Identity" in a Sceptical Age. London: Sage.

Pietilä, Ilkka. 2008. Between Rocks and Hard Places. Ideological dilemmas in men's talk about health and gender. Tampere: University of Tampere.

Riach, Kathleen, and Leanne Cutcher. 2014. "Built to last: ageing, class and the masculine body in a UK hedge fund." Work, Employment and Society 28(5): 771-787.

Robertson, Steve, Bob Williams, and John Oliffe. 2016. "The Case for Retaining a Focus on 'Masculinities' in Men's Health Research.” International Journal of Men's Health 15(1): 52-67.

Siltala, Juha. 1994. Miehen kunnia. Modernin miehen taistelu häpeää vastaan [Honour of a Man. Modern Man's Battle against Shame]. Helsinki: Otava.

Taylor, Dianna. 2009. “Normativity and Normalization." Foucault Studies (7): 45-63.

Turtiainen, Jussi, and Ari Väänänen. 2012. "Men of Steel?: The Masculinity of Metal Industry Workers in Finland after World War II." Journal of Social History 46(1): 449-472.

Waling, Andrea. 2019. "Rethinking Masculinity Studies: Feminism, Masculinity, and Poststructural Accounts of Agency and Emotional Reflexivity." Journal of Men's Studies 27(1): 89-107. 